\title{
Effect of Age on Learning to Drive a Virtual Coal Mine Shuttle Car
}

\author{
Christine M. Zupanc ${ }^{*}, 1$, Robin Burgess-Limerick ${ }^{2}$ and Guy Wallis ${ }^{1}$ \\ ${ }^{I}$ School of Human Movement Studies, The University of Queensland, Australia \\ ${ }^{2}$ Minerals Industry Safety and Health Centre, Sustainable Minerals Institute, The University of Queensland, Australia
}

\begin{abstract}
Many control devices produce movements that can be described as compatible, that is, movement of the control in one direction results in a congruent movement in the system. However, not all devices adhere to this direct relationship between control movement and system response. This study investigates age and practice effects on error and reaction times for a real-world vehicle steering system in which steering is not consistently compatible. A virtual reality simulation analogous to an underground coal mine shuttle car was used to collect short term (experiment 1) and longer term (experiment 2) practice where trials alternate between compatible and incompatible, and then changed to consistently compatible. Fifteen young and 15 older male adults participated in experiment 1, and 7 young and 7 older male adults participated in experiment 2. Younger adults made fewer errors in incompatible trials than older adults in experiment 1. Error rate increased for both groups when the trials changed to consistently compatible. No differences in reaction time were found. With more practice, no differences in error rate were found between the groups (experiment 2). Both errors and reaction time increased when the the trials changed to consistently compatible. This research suggests that performance differences between male adults close to retirement age and younger male adults may dissipate after practice. Performance decrements were found when the control-response relationship changed from alternating compatibility to consistently compatible, therefore, care must be taken in redesigning incompatible controls when operators may have achieved a high level of expertise.
\end{abstract}

Keywords: Age effect, alternating compatibility, compatibility, control-response relationship, driving simulation, learning, steering.

\section{INTRODUCTION}

Ensuring compatibility between control input and vehicle response is a fundamental human factors principle. However, some underground coal mine shuttle cars require the driver to operate a steering control that regularly alternates between compatible and incompatible (with changes in vehicle direction). A compatible steering control-response relationship exists where a clockwise rotation of the steering wheel (located directly in front of the driver) results in a change of direction to the drivers's right and a counterclockwise rotation turns the vehicle to the driver's left. Some shuttle cars have a compatible control-response relationship when going in one direction, but when traveling in the other direction the relationship is incompatible (that is, a clockwise rotation results in the vehicle turning left and a counter-clockwise rotation steers the vehicle right). Consistent with previous more general studies of compatibility [1], an investigation carried out using a virtual reality simulation of a situation analogous to the shuttle car (alternating compatible and incompatible trials) found that young adults made more steering errors and slower responses in the early stages of learning than when the control-response relationship was consistently compatible [2].

\footnotetext{
*Address correspondence to this author at the School of Human Movement Studies, The University of Queensland, St. Lucia QLD, 4072, Australia; Tel: +610733656240; Fax: +610733656877;

E-mail: czupanc@optusnet.com.au
}

The performance advantages found with compatible mapping relationships over incompatible relationships (compatibility effect) in visuo-motor tasks have been found to be resistant to practice. Although extended practice benefits response selection for consistently incompatible mapping, laboratory studies have found that performance when the mapping is incompatible does not reach that for consistently compatible mapping [1]. Results from a two choice spatial compatibility task [3], where participants carried out 2,400 trials over eight sessions, found that a large compatibility effect remained. It was suggested that since the compatibility effect in the last four sessions showed little change, it was unlikely that the effect would be eliminated with further practice. These results support an earlier investigation of practice effects on stimulus-response compatibility carried out by Fitts and Seeger, 1953 [4], where 32 training sessions over approximately $2 \frac{1}{2}$ months failed to extinguish the performance advantage of the most direct, compatible relationship. However, a visual-motor tracking adaptation study, where mapping alternated between a compatible and incompatible mapping, found improvements in performance with extended practice [5]. The authors speculated that with more than five hours of practice, performance in the incompatible mapping condition may decrease further to reach that of the baseline levels achieved in the normal mapping condition.

The world's population is aging, with a faster trend in developing countries than developed countries, and as a consequence, there will be increasing numbers of working older adults. Currently the proportion of workers in the 45 to 
75 age group in the Australian mining industry is 38\% [6] and given expected trends this proportion will increase. Therefore, designing interfaces and controls for older adults will become increasingly important [7]. Much of the aging research reports performance of participants over 65 years of age, however, there is a scarcity of research focusing on the mature age worker (55 to 65 years). Different cognitive functions have been shown to be more sensitive to aging than others for over 65 year olds. For example, semantic memory and verbal reasoning show little effects with age, while functions necessary for complex goal-orientated behaviours, such as attention, response selection, response suppression, and cognitive flexibility have been found to decline with age [8-13]. Another factor thought to be an important mechanism in explaining age related declines in cognitive abilities is a generalized slowing of processing speed $[8,11]$. However, older adults have been shown to achieve comparable performance with young adults in some perceptual-motor tasks $[17,21]$.

Laboratory tasks involving blocked compatible and blocked incompatible, or mixed compatible and incompatible mappings, found that older adults respond more slowly than younger adults [7]. When testing performance in perceptual-motor tasks, such as a pursuit rotor task [15, 16] and mirror tracing task [14] older adults could not achieve the performance of the younger adults, however, it was noted that some older adults were able to perform at a similar level to the younger adults [17]. Research into age effects in sensorimotor adaptation to distorted mappings also indicates that older adults exhibit poorer performance, and in some studies, reduced rates of learning than younger adults [18-20]. When the task was consistently incompatible, such as a mirror tracing task, older adults' performance improved over three days of practice, however, age effects were only found for tracing speed and not error rate [17]. In a sample-matching and oddity-matching task, with 40 hours of practice over two to four weeks, age effect were found, with older and younger adults improving at an equivalent rate; however, some of the older adults' performance fell within the performance distribution of the younger adults [21].
The research into performance characteristics of older adults ( $>65$ years) can be used as a predictor of physical and cognitive functioning for this age group, but it provides little information about performances for the pre-retirement age group (55-65 years).

There is potential for negative consequences when incompatible control response relationships are changed to compatible. Research into compatibility aftereffects in a twochoice task found that with one session of 300 trials for each of three days, reaction time and error rate for consistently compatible (uncrossed hands) and consistently incompatible (uncrossed hands) trials improved on the fourth day when the compatibility remained consistent, but performance deteriorated in the fourth session when trials changed to the opposite compatibility [22]. Participants were not able to easily switch from the learned incompatible mapping to what would have been considered an 'automatic' compatible mapping. This aftereffect is often found in adaptation research, were performance decrements result when the task changes from an incompatible to normal or compatible mapping for both younger adults $[23,24]$ and older adults [20].

In the coming years, with the increasing proportion of the workforce in the middle to older age groups, how these groups of older workers perform, and adapt to novel manmachine interactions, will become increasingly important. The aim of these experiments is to use a virtual reality simulation of a situation analogous to the shuttle car, with an alternating compatibility control-response relationship, to investigate how an older group of males' (close to retirement age) performance compares with a younger male group, both under the condition of short term practice (experiment 1), and longer term practice (experiment 2). The performance consequences, for older and younger groups, when the alternating control-response relationship is changed to consistently compatible, will also be investigated (experiment 1 and 2).

\section{SIMULATED TASK}

Some underground coal mine shuttle cars' steering configuration alternates between a compatible and

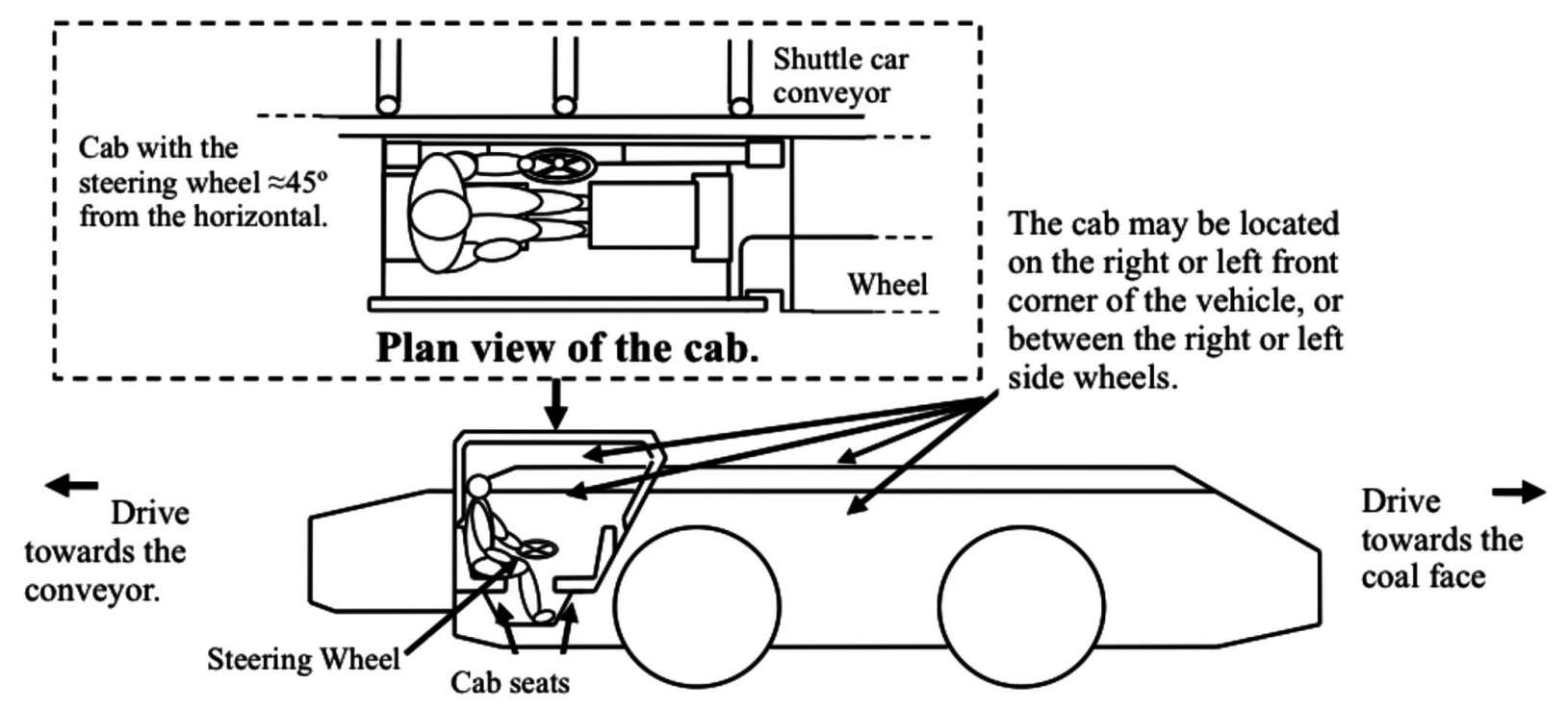

Fig. (1). Diagram of a shuttle car. 
incompatible control-response relationship. Shuttle cars are free steered vehicles used to transport coal from the coal development face to a conveyor. Fig. (1) illustrates a cab layout, and cab location, of some shuttle cars in which a steering wheel is used to steer the vehicle. In these shuttle cars the steering wheel is located to one side and between two facing seats, attached to the inside wall of the cab (perpendicular to the typical vehicle arrangement).

In traveling between the coal face and the conveyor the shuttle car does not turn around, and two facing seats in the cab allow the driver to change seats with each change of direction and always face the direction of travel. The steering mechanism does not change with each change in travel direction, and consequently to steer the car right requires a clockwise rotation when traveling in one direction and a counter-clockwise rotation when the car is traveling in the other direction. The Visual-Field Compatibility Principle [25] predicts that when driving the shuttle car forward towards the conveyor the control-response relationship is compatible (see Fig. 2A), however, when returning toward the face the relationship is incompatible (see Fig. 2B). Shuttle car drivers thus continually alternate between compatible and incompatible steering configurations with each change of direction.

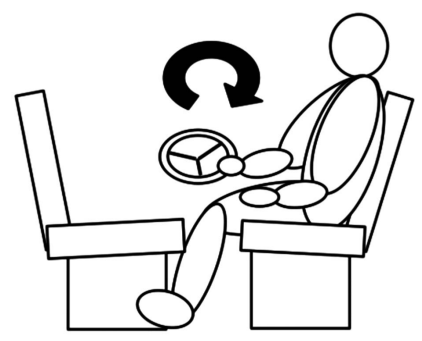

Fig. (2A). Compatible control-response relationship: clockwise rotation of the steering wheel turns the vehicle to the operator's right, and counter-clockwise rotation turns the vehicle to the operator's left.

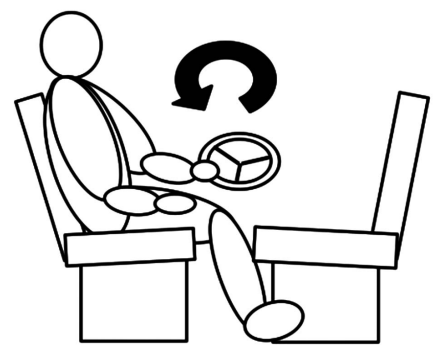

Fig. (2B). Incompatible control-response relationship: counterclockwise rotation of the steering wheel turns the vehicle to the operator's right, and clockwise rotation turns the vehicle to the operator's left.

This situation (alternating control-response compatibility) has been demonstrated to result in increased steering errors and slower responses in the early stages of learning as compared to a consistently compatible controlresponse condition [2].

\section{EXPERIMENT 1}

The purpose of Experiment 1 was to investigate the effects of age on performance, with short term practice, in a task where compatible trials alternated with incompatible trials, followed by consistently compatible trials.

\section{MATERIALS AND METHODOLOGY}

\section{Participants}

Fifteen young male adults (20 to 36 years, $M=26$ years), and fifteen older male adults (54 to 64 years, $M=60$ years) participated. Data from the first 16 trials of the young group have previously been reported [2]. The older adults were recruited from the Australasian Centre on Ageing's 50+ Registry, with the constraint on participating being that the volunteers self selected themselves as healthy, not susceptible to motion sickness, held a current driver's license and drove frequently. The older participants were either currently in full-time employment, part-time employment, or recently retired. The young adults were recruited from The University of Queensland's Psychology Research Participation Scheme and from the School of Human Movement Studies. Participation by the young adults also required that they hold a current driver's license and not be susceptible to motion sickness. All participants reported that they had not previously driven a shuttle car, and had normal or corrected-to-normal vision. Compensation was provided for participating (a cinema voucher or cash).

\section{Apparatus}

The experiment was carried out in a fixed-base driving simulator. The scene was rendered by a Silicon Graphics Onyx 350 equipped with InfiniteReality II graphics. The scene was projected onto a wall using a BARCO $808 \mathrm{~S}$ analogue projector. The projected image was $2.33 \mathrm{~m}$ high and $3.12 \mathrm{~m}$ wide ( $300 \mathrm{~mm}$ from the floor). The image frame rate was $72 \mathrm{~Hz}$ and the update rate of the simulation $24 \mathrm{~Hz}$. Image resolution was set at $1280 \times 1024$ pixels. The lateral position, longitudinal position, steering angle, and location of the miner were recorded at $24 \mathrm{~Hz}$.

Two Logitech MOMO Racing Force Feedback Steering Wheels were used as the input steering devices. A spinning knob was attached to the top of each steering wheel. The steering wheels were secured to the side of two tables, with the steering knobs $900 \mathrm{~mm}$ from the floor. One steering wheel was located on the left side of the participant, and the other on the right side of the participant, such that the participant could comfortably hold either knob and rotate the steering wheel without constraint. An adjustable chair was placed in front of the screen at a position where the participant's face was approximately $1.5 \mathrm{~m}$ from the screen. The chair was adjusted so that the participant's forearm was close to a horizontal position while holding the steering wheel knob. To partially replicate the restricted visibility of a shuttle car, a black partition (1.2 m high, $2.5 \mathrm{~m}$ wide) was placed $450 \mathrm{~mm}$ from the screen.

\section{Stimuli}

The simulated environment consisted of a straight, textured underground mine road, $5 \mathrm{~m}$ wide and $3 \mathrm{~m}$ high. The virtual shuttle car traveled at a constant speed of 10 $\mathrm{km} / \mathrm{hr}$, to simulate a shuttle car's recommended operating speed. The simulation included a pair of semicircular illuminated areas which represented the shuttle car's headlights and moved in accordance with the shuttle car's 
heading. A simulated "miner" randomly appeared six times on each trial, $400 \mathrm{~mm}$ to the left or right of the centre of the road to simulate a situation in which an avoidance manoeuvre is required. The miner appeared a simulated $15 \mathrm{~m}$ down the tunnel, was visible for $5.7 \mathrm{~s}$, and the time period between each appearance of the miner randomly varied from 9 to 15 s. Fig. (3) illustrates the simulated mine road, the miner, an illuminated region (which represents the vehicle's headlights), and a person holding the steering knob with her left hand.

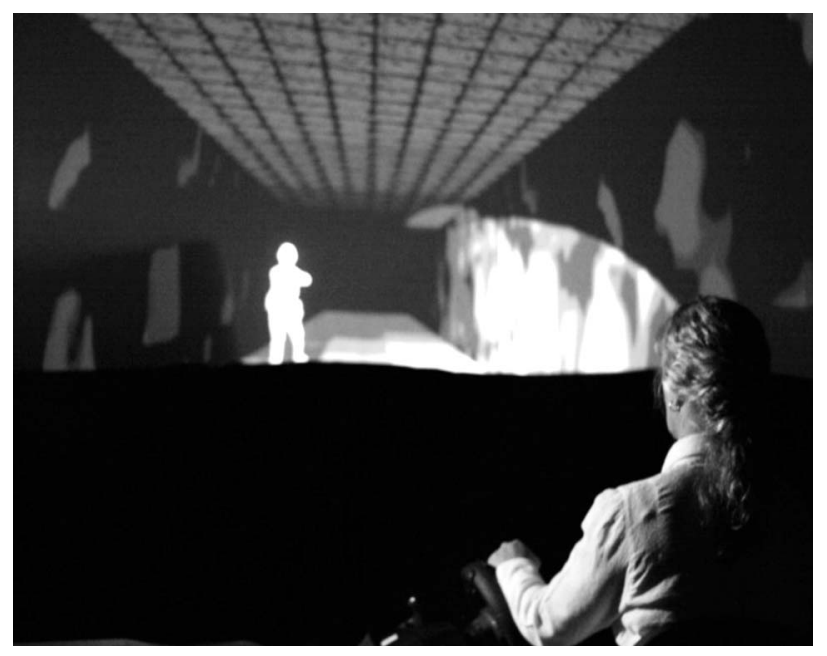

Fig. (3). Photograph of simulation in progress.

\section{Design and Procedure}

The experimental task was an emergency obstacle avoidance driving task involving driving a straight path along an underground mine road and avoiding a miner whenever he appeared. The experimental trials were set at approximately two minutes duration to simulate a typical shuttle car's travel time between the coal face and the conveyor.

There were two stages to the experiment. At the commencement of stage 1 participants were shown how to use the steering wheel (holding the steering knob with the adjacent hand) for both compatible and incompatible trials. Compatibility was isolated to a hand, that is, compatible trials were carried out by one hand and the incompatible trials by the other hand. The allocation of the compatible or the incompatible trial to either the right or left hand, and whether the participant started with a left or right hand, was randomized and counter balanced across participants.

Participants were instructed to drive down the centre of the road and maneuver, as promptly as possible, around the miner who would appear randomly on either side of the road. Information was not provided on how often the miner would appear, or the time interval between appearances.

For stage 1, 12 compatible trials alternated with 12 incompatible, followed by a short break of approximately two or three minutes. At the start of stage 2 participants were informed that the incompatible trials would now change to compatible, and that the steering would operates like a normal steering wheel, that is, a clockwise rotation turn the vehicle right, and a counter clockwise rotation turns it left.
Participants then carried out 12 compatible trials, that is, the side which had been compatible in stage 1 continued to be compatible during stage 2 , and the side which had previously been incompatible, was now compatible. For analysis the data from stage 2 were divided into trials executed with the hand that had performed compatible trials in stage 1, and trials carried out by the hand which had performed out incompatible trials in stage 1.

For compatible trials, a clockwise rotation of the steering wheel (while holding the knob) steers the vehicle right and a counter-clockwise rotation steers the vehicle left. For incompatible trials, a counter-clockwise rotation of the wheel steers the vehicle right and a clockwise wheel rotation steers the vehicle left.

\section{Dependent Measures}

Steering Direction Errors: a steering direction error was deemed to have occurred if participants made a steering input of 20 degrees or more that caused the shuttle car to turn towards the miner, $\geq 250 \mathrm{~ms}$ after the miner became visible. Recording of errors was conservative, that is, regardless of how many steering errors were actually made between 250 $\mathrm{ms}$ and $2 \mathrm{~s}$ after the miner appeared, only one error was recorded.

Reaction Time: reaction time data were calculated for avoidance manoeuvres when no steering error was made, and a marked change in steering wheel angle $\left(\geq 20^{\circ}\right)$ in the correct direction was evident following the appearance of the miner. Reaction time was defined as the time from the moment the miner first became visible to the moment when the participant started to steer in the correct direction.

\section{Data Analysis}

The percentage steering direction errors and reaction time data were collated into blocks ( 2 trials per block) and mixed design (repeated measures) analyses of variance (ANOVA) were carried out. Where data violated the assumption of sphericity, the Greenhouse-Geisser correction is reported.

\section{RESULTS}

\section{Steering Direction Errors}

The steering direction errors from two consecutive compatible (C) or incompatible (I) trials were grouped into each of six blocks in stage 1. The pattern of data grouping continued for stage 2, that is, two consecutive continuing compatible (C-C) trials, or two consecutive trials that had changed from incompatible to compatible (I-C) were grouped into each block. Steering direction errors were converted to a percentage of the total possible number of errors (12 per block data point). Fig. (4) shows the mean percentage steering direction errors for the young and older groups (error bars are $95 \%$ confidence intervals).

Three mixed design ANOVAs with 1 between-subjects factor (group) and 2 within-subject factors (compatibility and block) were carried out on the data from blocks 1 to 6 , blocks 6 and 7, and blocks 7 to 9 . Results are summarized in Table 1.

During stage 1, when trials alternated between compatible (C) and incompatible (I), overall fewer errors were made in $\mathrm{C}$ trials $(6.3 \%)$ than I trials $(18 \%)$, however, 


\section{Steering Direction Errors}

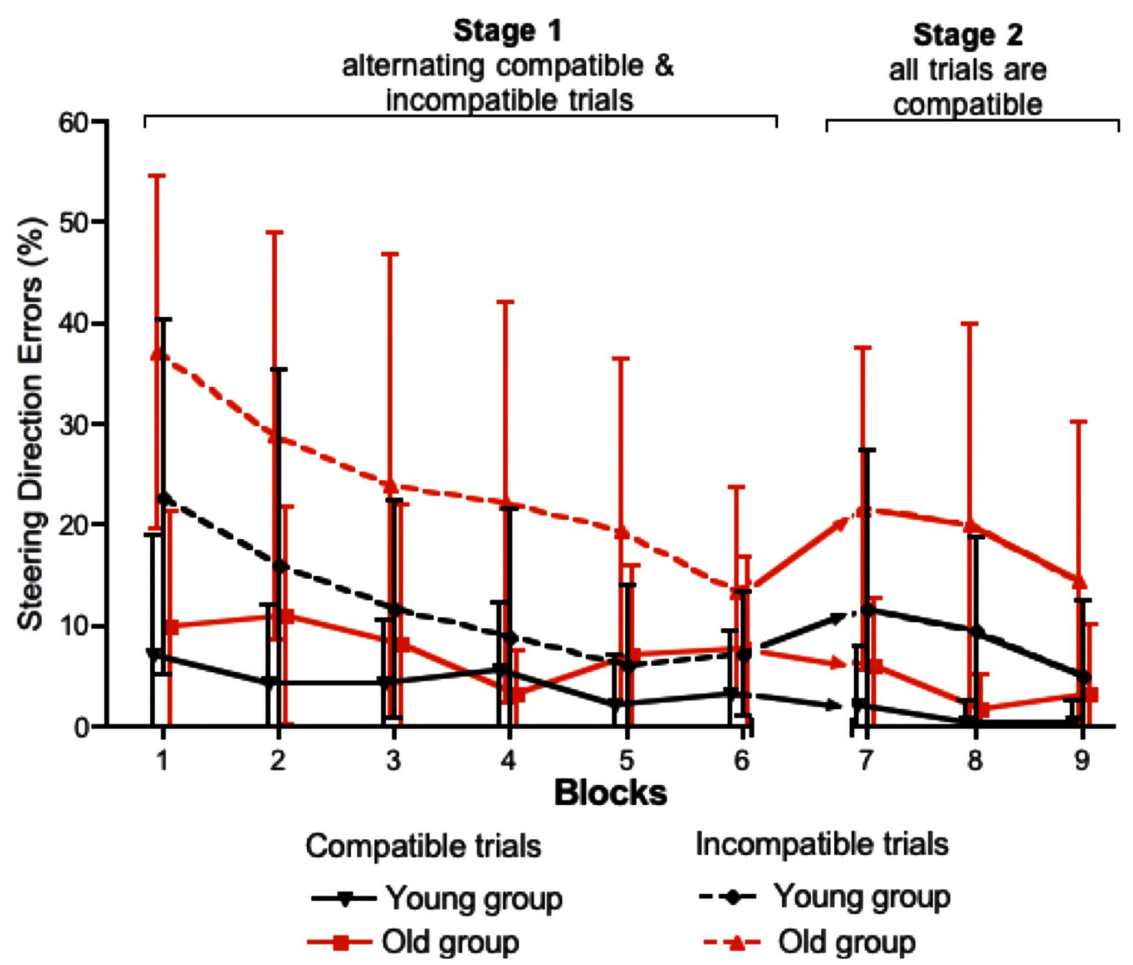

Fig. (4). Mean percentage steering direction errors for the young and old groups ( 2 trials per block, and error bars are $95 \%$ confidence intervals).

the compatibility $\mathrm{x}$ group interaction indicates that the difference between $\mathrm{C}$ and I trials was greater for the older adults. A significant group effect was found where older adults made more errors (16\%) than the younger adults $(8.3 \%)$. Error rate decreased significantly across the blocks, and the compatibility $\mathrm{x}$ block interaction indicates that the rate of improvement was greater for I trials. In block 6 , an unpaired t-test $(\mathrm{t}[58]=2.44, \mathrm{p}<0.02)$ revealed that, overall, older adults made more errors $(10.6 \%)$ than younger adults $(5.3 \%)$.

A compatibility effect was found between blocks 6 and 7 (when I trials in block 6 changed to I-C in block 7 and the $\mathrm{C}$ trials remained $\mathrm{C}-\mathrm{C}$ ), with more errors being made in I and I$\mathrm{C}$ trials $(13.5 \%)$, than $\mathrm{C}$ and $\mathrm{C}-\mathrm{C}$ trials $(5 \%)$. Overall the error rate increased, although this did not reach significance, and the compatibility $\mathrm{x}$ block interaction indicates that the increase occurred in I-C trials, rather than $\mathrm{C}-\mathrm{C}$ trials. The significant group effect indicates that older adults $(12 \%)$ made more errors than younger adults $(6 \%)$ during blocks 6 and 7.

In stage 2 , when all trials were compatible, significantly more errors were made by the hand that had changed from incompatible to compatible ( $\mathrm{I}-\mathrm{C}=14 \%)$ than the hand that remained compatible $(\mathrm{C}-\mathrm{C}=2 \%)$. Overall, there was a significant decrease in error rate across blocks 7 to 9 , and the near significant compatibility $\mathrm{x}$ block interaction suggests that most of the decrease occurred in the I-C trials. A significant group effect remained during stage 2, with the older adults (11\%) making more errors than the young adults $(5 \%)$. Within group paired t-tests were carried out to

Table 1. Summary of ANOVA Results for Steering Direction Error Data

\begin{tabular}{|c|c|c|c|c|c|c|c|c|c|c|c|c|}
\hline & \multicolumn{4}{|c|}{ Stage 1 (Blocks 1 - 6) } & \multicolumn{4}{|c|}{ Blocks 6 - 7} & \multicolumn{4}{|c|}{ Stage 2 (Blocks $7-9$ ) } \\
\hline Compatibility & 1,28 & 34.3 & .55 & $<.01$ & 1,28 & 25.0 & .47 & $<.01$ & 1,28 & 26.3 & .48 & $<.01$ \\
\hline Block & 5,140 & 11.1 & .28 & $<.01$ & 1,28 & 3.5 & .11 & .07 & $2,47 \wedge$ & 5.7 & .17 & $<.01$ \\
\hline Group & 1,28 & 6.7 & .19 & $<.02$ & 1,28 & 5.2 & .16 & .03 & 1,28 & 6.0 & .18 & .02 \\
\hline Compatibility x Group & 1,28 & 4.5 & .14 & .04 & 1,28 & 1.3 & .04 & .27 & 1,28 & 2.8 & .09 & .11 \\
\hline Block x Group & 5,140 & 0.5 & .02 & .76 & 1,28 & 0.4 & .01 & .54 & 2,56 & 0.1 & .01 & .91 \\
\hline Compatibility x Block x Group & 5,140 & 1.2 & .04 & .31 & 1,28 & 0.6 & .02 & .46 & 2,56 & 0.3 & .01 & .78 \\
\hline
\end{tabular}




\section{Reaction Time}

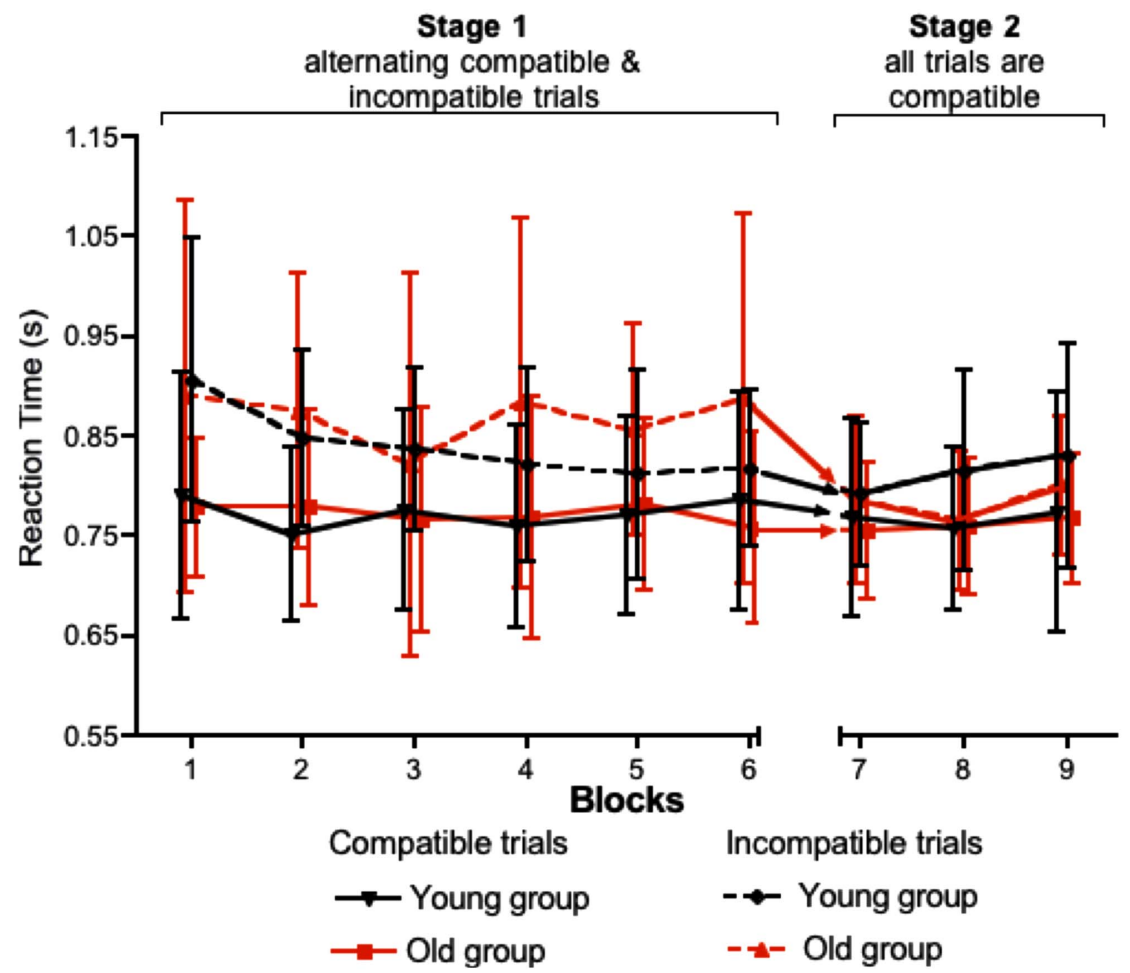

Fig. (5). Mean reaction time in seconds for the young and old groups ( 2 trials per block, and error bars are $95 \%$ confidence intervals).

investigate whether the error rate difference between $\mathrm{C}-\mathrm{C}$ and I-C trials remained during block 9. Results showed that the younger adults' and the older adults' performance in C-C trials was significantly less error prone than I-C trials $(\mathrm{t}[14]$ $=2.3, \mathrm{p}=.04$, and $\mathrm{t}[14]=2.6, \mathrm{p}=.02$ respectively).

\section{Reaction Time}

The reaction time data from two consecutive compatible (C) or incompatible (I) trials were grouped into each of six blocks in stage 1 . The pattern of data grouping continued for the three blocks in stage 2, that is, two consecutive continuing compatible (C-C) trials, or two consecutive trials that had changed from incompatible to compatible (I-C) were grouped into each block. Fig. (5) shows the mean reaction time for the younger and older groups (error bars are $95 \%$ confidence intervals).

Three mixed design ANOVAs with 1 between-subjects factor (group) and 2 within-subject factors (compatibility and block) were carried out on the data from blocks 1 to 6 , blocks 6 and 7, and blocks 7 to 9 . Results are summarized in Table 2 (below).

An overall significant compatibility effect was found in stage 1 (when trials alternated between $\mathrm{C}$ and I) where reaction time was faster in $\mathrm{C}$ trials $(0.77 \mathrm{~s})$ than I trials $(0.86$ s). However, there were no significant block or group effects.

For blocks 6 and 7 reaction time was significant faster for $\mathrm{C}$ and $\mathrm{C}-\mathrm{C}$ trials $(0.77 \mathrm{~s})$ than I and I-C trials $(0.8 \mathrm{~s})$, and a significant block effect was evident indicating that reaction time decreased across the blocks. The near significant compatibility $\mathrm{x}$ block interaction suggests that most of the decrease may have occurred in I-C trials. No overall difference in reaction time was evident between the groups.

During stage 2, when all trials were compatible, no significant difference in reaction time was found between $\mathrm{C}$ $\mathrm{C}$ and I-C trials, and no significant change occurred across the blocks. Again, no difference was found in reaction time between the younger and older adults.

\section{DISCUSSION}

The aim of experiment 1 was to investigate age effects (for male adults close to retirement age) with short term practice in a task where compatibility alternated, and the effect on performance when the task became consistently compatible. During stage 1 compatibility was isolated to one hand; that is, participants carried out compatible trials using one hand (either left or right) and incompatible trials with the other hand (either right or left), and compatible trials alternated with incompatible trials. Analysis of the steering direction errors during this stage identified that, within each group, fewer errors were made in compatible trials than in incompatible trials. During the approximately 50 minutes of driving, error rate in incompatible trials decreased for both groups, while the error rate in compatible trials remained fairly constant. This suggests that performance when there was a compatible relationship between control and response was probably close to baseline levels, allowing very little opportunity for improvement, while participants showed significant levels of learning (adaptation) when the relationship was incompatible. The older adults made significantly more errors overall than the younger adults, and most of this difference was evident in the incompatible trials. 
Table 2. Summary of ANOVA Results for Reaction Time Data

\begin{tabular}{|c|c|c|c|c|c|c|c|c|c|c|c|c|}
\hline & \multicolumn{4}{|c|}{ Stage 1 (Blocks 1 - 6) } & \multicolumn{4}{|c|}{ Block 6-7 } & \multicolumn{4}{|c|}{ Stage 2 (Blocks 7 - 9) } \\
\hline Block & $3,90 \wedge$ & 1.4 & .05 & .25 & 1,28 & 4.5 & .14 & $<.05$ & 2,56 & 1.8 & .06 & .18 \\
\hline Group & 1,28 & 0.3 & .01 & .61 & 1,28 & 0.1 & .01 & .8 & 1,28 & 0.9 & .03 & .36 \\
\hline Compatibility $\mathrm{x}$ Group & 1,28 & 0.5 & .02 & .48 & 1,28 & 2.0 & .07 & .17 & 1,28 & 0.4 & .01 & .54 \\
\hline Block x Group & 5,140 & 0.8 & .03 & .58 & 1,28 & 0.9 & .03 & .36 & 2,56 & 0.2 & .01 & .82 \\
\hline Compatibility x Block x Group & 5,140 & 1.1 & .04 & .38 & 1,28 & 2.1 & .07 & .16 & 2,56 & 1.0 & .04 & .37 \\
\hline
\end{tabular}

Error data in S-R compatibility research is often small and omitted from the analysis, and where errors have been analysed no age effect has been found. Smulders et al., 1999 [26] reports that when the stimulus is not degraded error rate performance of older adults ( $\mathrm{M}=70$ years) was no worse than the younger adults, and Christensen et al., 1996 [27] reported that overall the error rate of the older (68-80 years) and younger adults was similar. However, results from dynamic visuo-motor adaptation studies (to incompatible or distorted mapping) showed greater error rates (mean root square error) for older adults (ages ranged from 58 to 80) as compared to younger adults $[19,28,29]$, while older and younger adults' performance were not different during the baseline (compatible mapping) phase of a pointing task [28].

In the current experiment, where compatibility alternated, an age effect of increased errors was found for older adults, and remained for the final block of the alternating stage. Possibly, the older adults' greater error rate in the incompatible trials may be due to an increased susceptibility to lapses of intention, which may only be short lived [10], or a reduced capacity for goal maintenance and selection [30] leading to deficits in inhibition of dominant responses.

Analysis of the reaction time performance in stage 1 found that a compatibility effect was evident within each group. However, contrary to expectations no overall reaction time difference was found between the younger and older adults' compatible trials or incompatible trials. The non-significant group effect in this experiment is not consistent with the expectation that older adults would respond more slowly than younger adults in tasks involving blocked incompatible, or mixed compatible and incompatible trials [7, 26, 27, 31].

It has been suggested $[30,32]$ that a possible explanation for older adults' slower reaction times, coupled with a similar accuracy rate to younger adults in choice reaction tasks may be due to older adults adopting a more conservative response strategy. In the current experiment, to successfully maneuver around the miner, participants must respond quickly, but not necessarily immediately, upon presentation of the miner (from first appearance of the miner to passing the miner was approximately $5.7 \mathrm{~s}$ ). The urgency of the required steering maneuver was not high, allowing participants the opportunity to trade off speed for accuracy. The results suggest that neither the younger adults nor the older adults slowed their response rate in an endeavor to reduce their error rate in incompatible trials. In fact, the older adults maintained a similar response speed to the younger adults but made significantly more errors, particularly in incompatible trials.

During stage 2, for both groups, error rate increased significantly in the compatible trials for the hand that had previously carried out incompatible trials (I-C trials). Error rate decreased during stage 2 , however, during the final block more errors were still being made by the hand which had previously performed incompatible trials. This change in error rate performance is similar to that commonly found in adaptation studies, where an initial poorer performance is found when the condition changes from the adapted non-normal, or incompatible mapping, to an opposite or normal (compatible) mapping $[20,23,28,29,33]$. However, this performance decrement was not apparent in reaction time performance during stage 2 and reaction time reduced when the controlresponse relationship became consistently compatible, particularly for the hand which had previously carried out incompatible trials, resulting in no negative aftereffects for response rate.

\section{Experiment 2}

The purpose of Experiment 2 was to investigate the effects of age and extended practice in a task where compatible trials alternated with incompatible trials, the effect on performance when time stress was increased (reduced time to respond to avoid the obstacle), and the effect on performance when the hand that had carried out incompatible trials in previous sessions, carried out compatible trials for two sessions.

\section{MATERIALS AND METHODOLOGY}

\section{Participants}

Seven young male adults ( 20 to 31 years, $M=23$ years), and seven older male adults ( 58 to 65 years, $\mathrm{M}=62$ years) participated. One older participant withdrew after session G. The older adults were recruited via advertisements in The University of Queensland staff newsletter, and other general community contacts, with the constraint on participating being that the volunteers self selected themselves as healthy, not susceptible to motion sickness, held a current driver's license and drove frequently. All of the older participants were actively involved in the workforce, either on a full time or part time basis. The young adults were recruited from The University of Queensland's Psychology Research 
Participation Scheme and from the School of Human Movement Studies. Participation by the young adults also required that they hold a current driver's license and not be susceptible to motion sickness. All participants had reported that they had not previously driven a shuttle car, and had normal or corrected-to-normal vision. Cash payments were provided as compensation for participating.

\section{Apparatus and Stimuli}

The apparatus and stimulus were the same as that used in Experiment 1 except for the following: for sessions $\mathrm{A}$ to $\mathrm{E}$ the miner first appeared a simulated $15 \mathrm{~m}$ down the tunnel, was visible for $5.7 \mathrm{~s}$, and the time period between each appearance of the miner randomly varied from 9 to $15 \mathrm{~s}$; and for sessions $\mathrm{F}, \mathrm{G}$ and $\mathrm{H}$ the miner first appeared a simulated $9 \mathrm{~m}$ down the tunnel, was visible for $3.4 \mathrm{~s}$, and the time period between each appearance of the miner randomly varied from 11 to $17 \mathrm{~s}$.

\section{Design and Procedure}

The experimental task was similar to Experiment 1, and involved:

five sessions (A to $\mathrm{E}$ ) in which 12 compatible trials alternated with 12 incompatible trials, and the miner appeared a simulated $15 \mathrm{~m}$ down the tunnel, was visible for $5.7 \mathrm{~s}$ and the time period between each appearance of the miner randomly varied from 9 to $15 \mathrm{~s}$;

one session (F) in which 12 compatible trials alternated with 12 incompatible trials, and a task time stress was increased with the miner appearing a simulated $9 \mathrm{~m}$ down the tunnel, was visible for approximately $3.4 \mathrm{~s}$ and the time period between each appearance of the miner randomly varied from 11 to $17 \mathrm{~s}$; and

(c) two sessions ( $\mathrm{G}$ and $\mathrm{H}$ ) in which the hand that had previously carried out incompatible trials now carried out compatible trials, resulting in a total of 24 compatible trials in each session. The time stress introduced during session $\mathrm{F}$ (with the miner being a simulated $9 \mathrm{~m}$ ahead when first becoming visible to participants) was maintained during sessions $G$ and H.

Sessions were held not less than 24 hour apart over a period of two to three weeks. Scheduling sessions depended upon when participants were available, with most sessions carried out in the morning or early afternoon. The allocation of the compatible or the incompatible trial to either the right or left hand, and whether the participant started with a left or right hand, was randomized and counter balanced across participants.

\section{Dependent Measures and Data Analysis}

Dependent measures were as described in Experiment 1.

The percentage steering direction errors and reaction time data were collated into sessions ( 24 trials per session) and mixed design (repeated measures) analyses of variance (ANOVA) were carried out. Where data violated the assumption of sphericity, the Greenhouse-Geisser correction is reported.

\section{Steering Direction Errors}

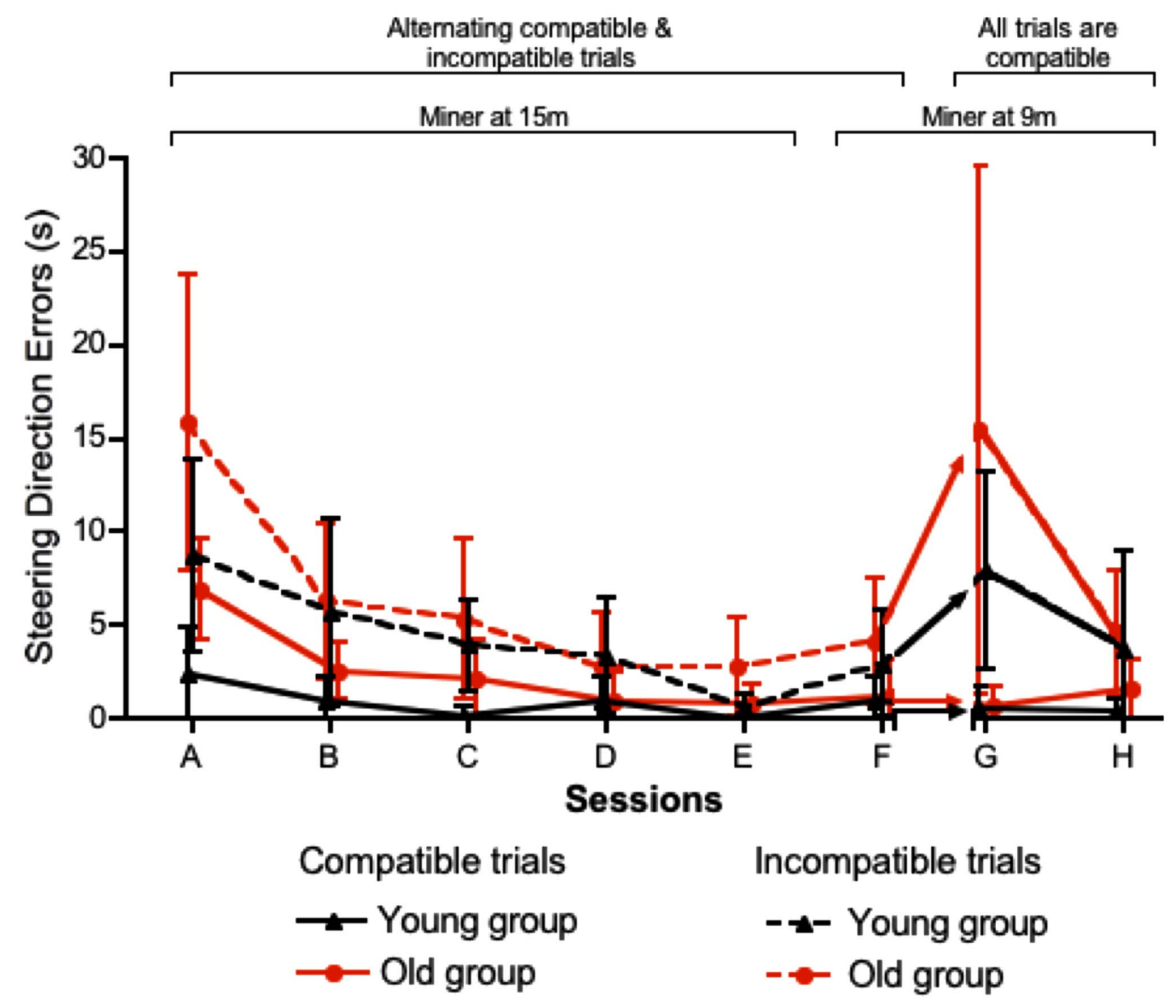

Fig. (6). Mean percentage steering direction errors for younger and older adults (24 trials per session, and error bars are $95 \%$ confidence intervals). 


\section{RESULTS}

\section{Steering Direction Errors}

The steering direction errors for all compatible (C) and incompatible (I) trials were averaged for sessions A to F. The pattern of data grouping continued for sessions $\mathrm{G}$ and $\mathrm{H}$, that is, all compatible (C-C) trials were averaged for each session, and all compatible (I-C) trials, carried out by the hand that had performed incompatible trials, were averaged for each session. Steering direction errors were converted to a percentage of the total possible number of errors (72 per session data point). Fig. (6) shows the mean percentage steering direction errors for the younger and older groups.

Four mixed design ANOVAs with 1 between-subjects factor (group) and 2 within-subject factors (compatibility and session) were carried out on the data from sessions A to H. Results are summarized in Table 3 below.

Sessions $A$ to $E$ (miner at $15 \mathrm{~m}$ ). A compatibility effect was evident in that fewer errors were made in $\mathrm{C}$ trials $(1.8 \%)$ than I trials $(5.6 \%)$, and the overall error rate decreased significantly across sessions. The compatibility $\mathrm{x}$ session interaction indicated that although the error rate in both $\mathrm{C}$ and I trials decreased, most of the improvement occurring in I trials. The large partial eta squared value for the main effect of group suggests that with an increased number of participants the effect could reach significance. For session $\mathrm{A}$, an unpaired t-test on all $\mathrm{C}$ and I trials revealed that older adults made more errors in this session than younger adults $(\mathrm{t}[26]=2.45, \mathrm{p}=0.021)$. For sessions $\mathrm{A}$ to $\mathrm{E}$ a session $\mathrm{x}$ group interaction was evident, where the older adults' error rate decreased across sessions at a greater rate than the younger adults.

Sessions $E$ (miner at $15 \mathrm{~m}$ ) and $F$ (miner at $9 \mathrm{~m}$ ). The compatibility effect was retained across sessions $\mathrm{E}$ and $\mathrm{F}$, with fewer errors being made in $\mathrm{C}$ trials $(0.75 \%)$ than I trials $(2.6 \%)$. The main effect of session indicates that when the time stress was increased a significant increase in error rate occurred. No overall difference in error rate was found between the groups. A paired t-test analysis of all $\mathrm{C}$ and all I trials in session $\mathrm{F}$ found that in the final session fewer errors were made in $\mathrm{C}$ trials than I trials $(\mathrm{t}[13]=2.76, \mathrm{p}=0.016)$.

Sessions $F$ and $G$ (miner at $9 \mathrm{~m}$ ). During sessions $\mathrm{F}$ and $\mathrm{G}$ (when the hand that carried out incompatible trials now carried out compatible trials), fewer errors were made in $\mathrm{C}$ and $\mathrm{C}-\mathrm{C}$ trials $(0.84 \%)$ than I and I-C trials $(7.6 \%)$. A significant main effect of session was found, and the compatibility $\mathrm{x}$ session interaction indicates that increased error rate occurred in I-C trials in session G. No significant group effect was found.

Sessions $G$ and $H$ (miner at $9 \mathrm{~m}$ ). One older participant did not participate in session $H$. During the final two sessions, when all trials are compatible, more errors were made in I-C trials $(6.75 \%)$ than C-C trials $(0.83 \%)$, a significant decrease in error rate was found, and the compatibility $\mathrm{x}$ session interaction indicates that the decrease occurred in I-C trials. Again, no significant group effect was evident. During the second 50 minute session $(\mathrm{H})$, a significant error rate difference remained between I-C and C-C trials ( $\mathrm{t}[12]=2.4, \mathrm{p}=0.034)$ indicating that although all trials were compatible a negative aftereffect on performance remained for the hand that had previously carried out incompatible trials in sessions $\mathrm{A}$ to $\mathrm{F}$.

Table 3. Summary of ANOVA Results for Steering Direction Error Data

\begin{tabular}{|c|c|c|c|c|c|c|c|c|}
\hline & \multicolumn{4}{|c|}{ Sessions A - E } & \multicolumn{4}{|c|}{ Sessions E - F } \\
\hline Session & $2,26 \wedge$ & 32.0 & .73 & $<.01$ & 1,12 & 8.9 & .43 & .01 \\
\hline Group (Age) & 1,12 & 3.7 & .24 & .08 & 1,12 & 2.3 & .16 & .16 \\
\hline Compatibility x Group & 1,12 & 0.1 & .01 & .81 & 1,12 & 1.0 & .07 & .35 \\
\hline Session x Group & $2,26 \wedge$ & 5.1 & .3 & .01 & 1,12 & 0.8 & .07 & .38 \\
\hline \multirow[t]{2}{*}{ Compatibility x Session x Group } & 4,48 & 0.8 & .06 & .53 & 1,12 & 0.1 & .01 & .8 \\
\hline & \multicolumn{4}{|c|}{ Sessions $\mathbf{F}-\mathbf{G}$} & \multicolumn{4}{|c|}{ Sessions $\mathbf{G}-\mathbf{H}$} \\
\hline Group (Age) & 1,12 & 1.6 & .12 & .23 & $1,11^{\frac{\pi}{\pi}}$ & 0.8 & .07 & .38 \\
\hline Compatibility x Session & 1,12 & 13.5 & .53 & $<.01$ & $1,11^{\text {th }}$ & 16.7 & 6 & $<.01$ \\
\hline Compatibility x Group & 1,12 & 1.4 & .1 & .26 & $1,11^{\text {光 }}$ & 0.2 & .02 & .68 \\
\hline Session $x$ Group & 1,12 & 1.6 & .12 & .23 & $1,11^{\text {光 }}$ & 0.1 & .01 & .78 \\
\hline Compatibility $\mathrm{x}$ Session $\mathrm{x}$ Group & 1,12 & 1.9 & .14 & .19 & $1,11^{\frac{\pi t}{t h}}$ & 1.3 & .1 & .29 \\
\hline
\end{tabular}

$\lambda$ Greenhouse-Geisser corrected df

${ }^{\pi} 1$ older participant withdrew after session $\mathrm{G}$; the participant's data were deleted from analysis of sessions $\mathrm{G}$ and $\mathrm{H}$. 


\section{Reaction Time}

The reaction time data for all compatible (C) and incompatible (I) trials were averaged for sessions A to F. The pattern of data grouping continued for sessions $G$ and $H$, that is, all compatible (C-C) trials were averaged for each session, and all compatible (I-C) trials, carried out by the hand that had performed incompatible trials, were averaged for each session. Fig. (7) shows the mean reaction time for the young and older groups.

Four mixed design ANOVAs with 1 between-subjects factor (group) and 2 within-subject factors (compatibility and session) were carried out on the data from sessions A to H. Results are summarized in Table 4 below.

Sessions $A$ to $E$ (miner at $15 \mathrm{~m}$ ). A compatibility effect was evident where participants responded faster in $\mathrm{C}$ trials $(0.73 \mathrm{~s})$ than I trials $(0.79 \mathrm{~s})$. Reaction time decreased significantly across sessions, and the compatibility $\mathrm{x}$ session interaction indicates that most of the improvement occurred in I trials. No significant difference in reaction time was found between the younger and older adults.

Sessions $E$ (miner at $15 \mathrm{~m}$ ) and $F$ (miner at $9 \mathrm{~m}$ ). The compatibility effect remained during sessions $\mathrm{E}$ and $\mathrm{F}$, with participants responding more quickly during $C$ trials $(0.7 \mathrm{~s})$ than I trials $(0.73 \mathrm{~s})$. Reaction time was faster in session $\mathrm{F}$ (with the increased time stress) than session E. No overall difference in performance was found between the groups. A paired t-test analysis of all $\mathrm{C}$ and $\mathrm{I}$ trials in session $\mathrm{F}$ found that in the final session reaction time in $\mathrm{C}$ trials was faster than $\mathrm{I}$ trials $(\mathrm{t}[13]=$ $3.18, \mathrm{p}<0.01)$.

Sessions $F$ and $G$ (miner at $9 \mathrm{~m}$ ). During sessions $\mathrm{F}$ and $\mathrm{G}$ (when the hand that carried out incompatible trials now carried out compatible trials), faster responses were made during $\mathrm{C}$ and $\mathrm{C}-\mathrm{C}$ trials $(0.68 \mathrm{~s})$, than I and I-C trials $(0.74 \mathrm{~s})$. Reaction time increased significantly across sessions, and the compatibility $\mathrm{x}$ session interaction indicates that most of the effect occurred in I-C trials in session G. No group effect was found.

Sessions $G$ and $H$ (miner at $9 \mathrm{~m}$ ). One older participant did not participate in session H. During the final 2 sessions (when all trials were compatible) slower responses were still found in I-C trials $(0.74 \mathrm{~s})$ compared to $\mathrm{C}-\mathrm{C}(0.68 \mathrm{~s})$. No overall change in reaction time occurred across the sessions, however, a significant compatibility $\mathrm{x}$ session interaction showed that overall reaction time for $\mathrm{C}-\mathrm{C}$ trials increased slightly while it decreased in I-C trials. A significant 3 way interaction of compatibility $\mathrm{x}$ session $\mathrm{x}$ group was found. The younger adults' reaction time for $\mathrm{C}-\mathrm{C}$ trials was faster in both sessions than the $\mathrm{I}-\mathrm{C}$ trials, however, the older adults' reaction time for $\mathrm{C}-\mathrm{C}$ trials increased between sessions $\mathrm{G}$ and $\mathrm{H}$ while it decreased during I$\mathrm{C}$ trials. Overall, the younger group's performance did not change while the older adults made significant improvements in $\mathrm{I}-\mathrm{C}$ trials. A paired t-test on all C-C and I-C trials in session $\mathrm{H}$ revealed that a during the final session overall reaction time for $\mathrm{C}-\mathrm{C}$ trials were faster than I-C trials $(\mathrm{t}[12]=2.94, \mathrm{p}<.02)$.

\section{DISCUSSION}

The aim of Experiment 2 was to investigate age and practice effects in an alternating compatibility task, the effect of increased time stress on performance, and the consequences of changing the task to consistently compatible.

During the alternating stage, no overall significant difference in error rate or reaction time was found between the younger and older adults, however, analysis of error rate in the

\section{Reaction Time}

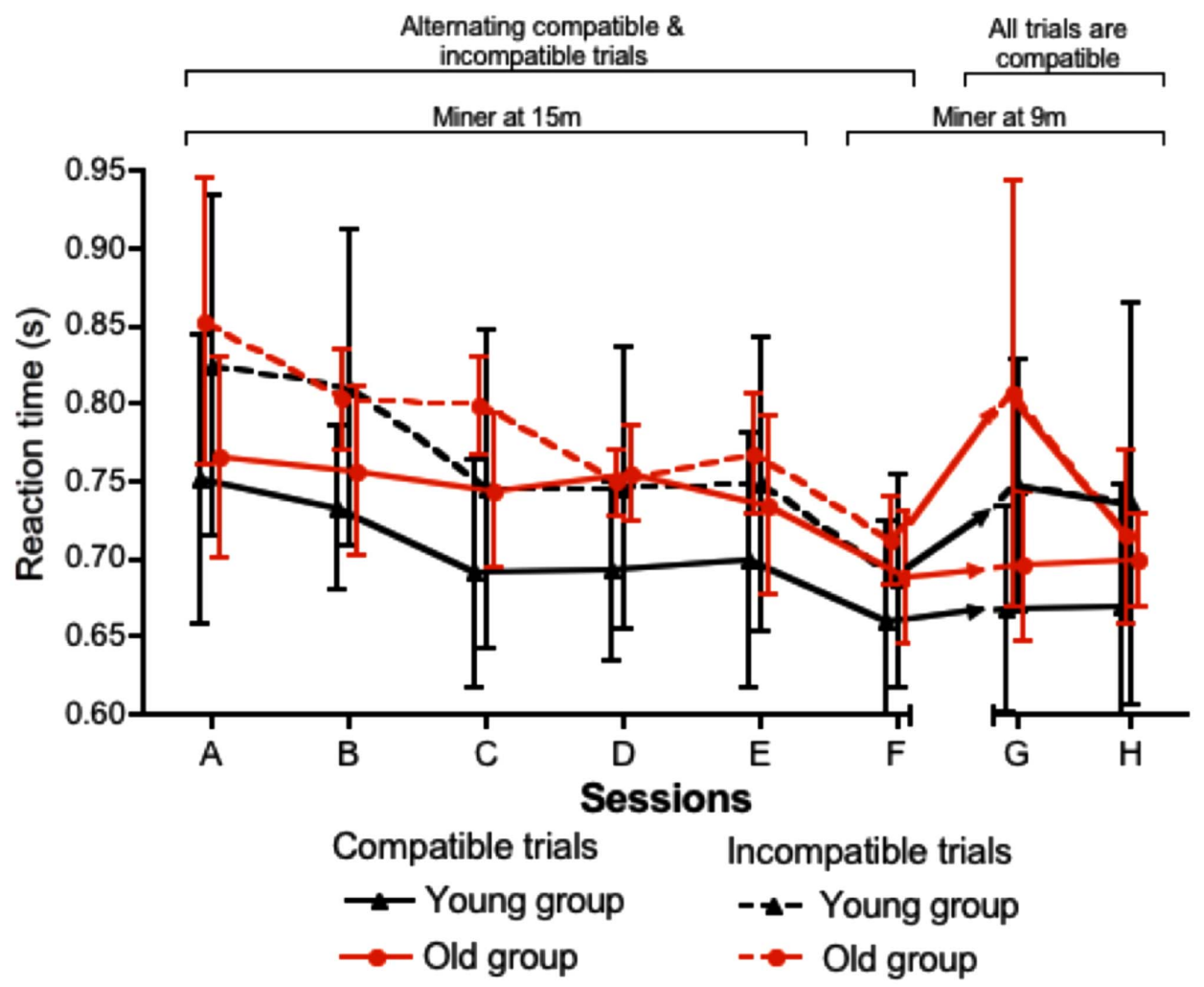

Fig. (7). Mean reaction time in seconds for the young and old groups (24 trials per session, and error bars are $95 \%$ confidence intervals). 
first session found that older adults made more errors than younger adults. This error rate performance difference when compatibility alternated was extinguished by the second session. Given more than one session of practice, the older adults and younger adults showed similar levels of adaptation to the task. These results do not support the commonly found performance decrements with age in some complex tasks [7-9, 11, 14].

Although error rate and reaction time decreased significantly across the alternating sessions (sessions A to F), a compatibility effect for both errors and reaction time was not eliminated at session F. During session F the task time stress was increased, with the miner becoming visible at a simulated nine metres as compared to fifteen metres during sessions $\mathrm{A}$ to $\mathrm{E}$, and it was evident that participants further reduced their reaction time in response to the time stress, however the consequence was an increased error rate, particularly in incompatible trials. This result suggests that although adaptation to the task occurred over the training sessions, when participants were required to respond faster they became more error prone.

The results from this experiment support S-R compatibility research $[3,4]$ which found that extended practice did not extinguish the compatibility effect between compatible and incompatible mappings. Adaptation researchers [23, 24, 34], on the other hand, suggest that practice results in high levels of performance improvement in tasks where the normal mapping has been distorted. Cunningham and Welch, 1994 [5], however, found that after six practice sessions in a visual-motor tracking task where short temporal periods of normal (compatible) mapping alternated with rotated (incompatible) mapping, performance in incompatible trials did not reach that for compatible trials. They speculate that more practice would result in equivalent performance between the opposing mappings. This experimental result does not support this suggestion. After six 50 minute training sessions held on separate days, error rate and reaction time compatibility effects were still evident.

Once the task changed to consistently compatible, that is, the hand that carried out incompatible trials during sessions A to F carried out compatible trials during sessions $\mathrm{G}$ and $\mathrm{H}$, the expected initial performance decrements were found. For trials carried out by the hand which had previously carried out incompatible trials, error rate and reaction time increased significantly. During the final session most of the error rate aftereffect was extinguished, however, no overall improvement in response rate was found.

Negative error rate after-effects are commonly found in adaptation studies when incompatible mappings relationships are changed to compatible $[23,24]$. This effect is generally short lived, as can be seen in error rate performance. Interestingly, during the second one hour session, where all trials were compatible, the older adults showed improvements in response speed for the changed trials (I-C) but not the trials that had remained compatible throughout (C-C). The younger adults, on the other hand, showed little improvement in the changed trials (I-C) with their reaction time remaining slower than their reaction time for incompatible trials during the alternating session F. It appeared that the older adults were able to achieve a similar response rate for all trials during the final session, while the younger adults maintained a reaction time performance difference between $\mathrm{C}-\mathrm{C}$ and I-C trials.

\section{GENERAL DISCUSSION AND CONCLUSION}

The older age group of interest for participation in these experiments was the 55 to 65 year age group. Workers in this group are close to, or have recently retired from the workforce, and with an aging population are more likely to remain longer in the workforce. Much of the research into the effects of age on

Table 4. Summary of ANOVA Results for Reaction Time Data

\begin{tabular}{|c|c|c|c|c|c|c|c|c|}
\hline & \multicolumn{4}{|c|}{ Sessions A - E } & \multicolumn{4}{|c|}{ Sessions E - F } \\
\hline & df & $\mathbf{F}$ & $\eta_{\mathrm{p}}^{2}$ & $\mathbf{p}$ & df & $\mathbf{F}$ & $\eta_{\mathrm{p}}^{2}$ & $\mathbf{p}$ \\
\hline Compatibility & 1,12 & 16.4 & .58 & $<.01$ & 1,12 & 13.7 & .53 & $<.01$ \\
\hline Session & 4,48 & 12.3 & .51 & $<.01$ & 1,12 & 35.4 & .75 & $<.01$ \\
\hline Group (Age) & 1,12 & 0.8 & .06 & .39 & 1,12 & 0.8 & .06 & .4 \\
\hline Compatibility $\mathrm{x}$ Session & 2,24 & 3.7 & .23 & .04 & 1,12 & 1.3 & .1 & .28 \\
\hline Session x Group & 4,48 & 1.1 & .09 & .35 & 1,12 & 0.1 & .01 & .98 \\
\hline \multirow[t]{3}{*}{ Compatibility $\mathrm{x}$ Session $\mathrm{x}$ Group } & 4,48 & 1.7 & .12 & .18 & 1,12 & 0.2 & .02 & .68 \\
\hline & \multicolumn{4}{|c|}{ Sessions F - G } & \multicolumn{4}{|c|}{ Sessions $\mathbf{G}-\mathbf{H}$} \\
\hline & df & $\mathbf{F}$ & $\eta_{p}^{2}$ & $\mathbf{p}$ & df & $\mathbf{F}$ & $\eta_{p}^{2}$ & $\mathbf{p}$ \\
\hline Compatibility x Session & 1,12 & 11.34 & .49 & $<.01$ & 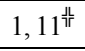 & 11.8 & .52 & $<.01$ \\
\hline Compatibility x Group & 1,12 & 0.5 & .04 & .49 & $1,11^{\text {光 }}$ & 1.6 & .13 & .24 \\
\hline Session $\mathrm{x}$ Group & 1,12 & 0.4 & .04 & .52 & $1,11^{\text {五 }}$ & 0.2 & .02 & .65 \\
\hline Compatibility $\mathrm{x}$ Session $\mathrm{x}$ Group & 1,12 & 0.7 & .05 & .43 & $1,11^{\text {常 }}$ & 5.2 & .32 & $<.05$ \\
\hline
\end{tabular}

Greenhouse-Geisser corrected df.

${ }^{\text {th }} 1$ older participant withdrew after session $\mathrm{G}$; the participant's data were deleted from analysis of sessions $\mathrm{G}$ and $\mathrm{H}$. 
performance involves age groups older than 65 years, and information about performance of these older groups may say little about performance of those people who may continue in the workforce into their mid 60's.

The experimental task was a dynamic task requiring participants to maintain a lateral position while driving down a simulated tunnel and make an emergency avoidance manoeuvre around a miner whenever he appeared. The control-response relationship alternated between compatible and incompatible, and the difficulty of this task is indicated by the high degree of steering direction errors made in incompatible trials early in practice, and the increased speed of responses participants were able to achieve after two 50 minute practice sessions.

The important results from these two experiments are that performance differences between older adults $(\mathrm{M}=60)$ and the younger adults are only evident for errors in incompatible trials during the first 50 minutes of training. Similar performance for both groups during the remaining training sessions indicates that the older adults were able to overcome their initial detriments in response selection. Compatibility effects were found for both error rate and reaction time, and although improvements in error rate occurred, the effect was not extinguished with six 50 minute practice sessions. Possibly, with further practice performance during incompatible control-response situations would improve, however, it is uncertain whether an incorrect response would occur when other non-optimal workplace factors such as stress, fatigue, or emergency situations are involved.

The negative consequences of changing from incompatible mapping to a compatible mapping after adaptation has also been confirmed in both experiment 1 and 2 , with significantly more steering direction errors made by the hand that had previously carried out incompatible trials. Participants had achieved levels of adaptation to the opposite mapping during the alternating stage, and then had difficulty inhibiting this learned mapping between control and response. A different pattern of reaction time changes was found between experiment 1 and 2 . When participants received only 50 minutes of practice with the incompatible mapping (in an alternating situation) reaction time for both groups improved once the mapping was changed to compatible. Possibly, one session of practice was not sufficient to consolidate the new learned relationship. However, when participants received six 50 minute practice sessions in the alternating situation, significantly slower responses were made by the hand that had changed from an incompatible to a compatible mapping. Participants may have actively slowed their responses in an endeavor to reduce their error rate and inhibit incorrect responses. Interestingly, the younger adults maintained this slower response rate in the final session while the older adults improved their reaction time for the changed mapping.

In conclusion, the implications are that incompatible control-response relationships may, at least in the early stages of learning, impact more on older workers than younger workers. Extended practice reduced, but did not eliminate, compatibility effects found in this task. Consideration should also be given to the potential for poorer performance by operators who may have developed high degrees of adaptation to an incompatible situation when redesigning controls to a compatible controlresponse relationship. The solution may be to provide a completely different steering mechanism rather than simply design the current mechanism to be always compatible.

\section{ACKNOWLEDGEMENTS}

This research was supported by Injury Prevention and Control (Australia) Ltd.

\section{CONFLICT OF INTEREST}

None declared.

\section{REFERENCES}

[1] Proctor RW, Vu KPL. Stimulus-response compatibility principles. data, theory, and application. Boca Raton FL: CRC Press 2006.

[2] Zupanc CM, Burgess-Limerick R, Wallis G. Performance consequences of alternating directional control-response compatibility: Evidence from a coal mine shuttle car simulator. Hum Fact 2007; 49: 628-36.

[3] Dutta A, Proctor RW. Persistence of stimulus-response compatibility with extended practice. J Exp Psychol Learn Mem Cogn 1992; 18: 8019.

[4] Fitts PM, Seeger CM. S-R Compatibility: spatial characteristics of stimulus and response codes. J Exp Psychol 1953; 46: 199-210.

[5] Cunningham HA, Welch RB. Multiple concurrent visual-motor mappings: implications for models of adaptation. J Exp Psychol Hum Percept Perform 1994; 20: 987-999

[6] Australian Bureau of Statistics. 4837.0.55.001 Health of Mature Age Workers in Australia: A snapshot, 2004-2005. Latest issue 29/07/2008. [Retrieved 2011 May 17] available from: http://www.abs.gov.au/ausst ats/abs@.nsf/mf/4837.0.55.001/\#PARTICIPATION

[7] Proctor RW, Vu, KP, Pick DF. Aging and response selection in spatial choice tasks. Hum Fact 2005; 47: 250-269.

[8] Raz N. Aging of the brain and its impact on cognitive performance: Integration of structural and functional findings. In: Craik FI, Salthouse TA, Eds. The handbook of aging and cognition. New Jersey: Lawrence Erlbaum Association 2000; pp. 1-90.

[9] Span MM, Ridderinkhof KR, van der Molen MW. Age-related changes in the efficiency of cognitive processing across the life span. Acta Psychol 2004; 117: 155-83.

[10] West R. Age differences in lapses of intention in the Stroop task. J Gerontol 1999; 54B: P34-P43.

[11] Salthouse TA. The processing-speed theory of adult age differences in cognition. Psychol Rev 1996; 103: 403-28.

[12] Hultsch DF, MacDonald SWS, Dixon RA. Variability in reaction time performance of younger and older adults. J Gerontol 2002; 57B: P101P115.

[13] Band GPH, Ridderinkhof KR, Segalowitz S. Explaining neurocognitive aging: Is one factor enough? Brain Cognit 2002; 49: 259-67.

[14] Kennedy KM, Raz N. Age, sex and regional brain volumes predict perceptual-motor skill acquisition. Cortex 2005; 41: 560-9.

[15] Durkin M, Prescott L, Furchtgott E, Cantor J, Powell DA. Performance but not acquisition of skill learning is severely impaired in the elderly. Arch Gerontol Geriatr 1995; 20: 167-83.

[16] Raz N, Williamson A, Gunning-Dixon F, Head D, Acker JD. (2000). Neuroanatomical and cognitive correlates of adult age differences in acquisition of a perceptual-motor skill. Microsc Res Tech 2000; 51: 8593.

[17] Rodrigue KM, Kennedy KM, Raz N. Aging and longitudinal change in perceptual-motor skill acquisition in health adults. J Gerontol 2005; 60B: 174-81.

[18] Bock O, Schneider S. Sensorimotor adaptation in young and elderly humans. Neurosci Biobehav Rev 2002; 26: 761-7.

[19] McNay EC, Willingham DB. Deficit in learning of a motor skill requiring strategy, but not of perceptuomotor recalibration with Aging. Learn Mem 1998; 4: 411-20.

[20] Seidler RD. Differential effects of age on sequence learning and sensorimotor adaptation. Brain Res Bull 2006; 70: 337-46.

[21] Baron A, Menich SR. Perone M. Reaction times of younger and older men and temporal contingencies of reinforcement. J Exp Anal Behav 1983; 40: 275-87.

[22] Proctor RW, Dutta A. Do the same stimulus-response relations influence choice reactions initially and after practice? J Exp Psychol Learn Mem Cogn 1993; 19: 922-30.

[23] Bock O, Worringham C, Thomas M. Concurrent adaptations of left and right arms to opposite visual distortions. Exp Brain Res 2005; 162: 5139 . 
[24] Woolley DG, Tresilian JR, Carson RG, Riek S. Dual adaptation to two opposing visuomotor rotations when each is associated with difference regions of workspace. Exp Brain Res 2006; 179: 155-65.

[25] Worringham CJ, Beringer DB. Directional stimulus-response compatibility: A test of three alternative principles. Ergonomics 1998; 41: 864-80.

[26] Smulders FTY, Kenemans JL, Schmidt WF, Kok A. Effects of task complexity in young and old adults: Reaction time and P300 latency are not always dissociated. Psychophysiology 1999; 36: 118-25.

[27] Christensen CA, Ford JM, Pfefferbaum A. The effect of stimulusresponse incompatibility on $\mathrm{P} 3$ latency depends on the task but not on age. Biol Psychol 1996; 44: 121-41.

[28] Bock O, Girgenrath M. Relationship between sensorimotor adaptation and cognitive functions in younger and older subjects. Exp Brain Res 2006; 169: 400-6.
[29] Buch ER, Young S, Contreras-Vidal JL. Visuomotor adaptation in normal aging. Learn Mem 2003; 10: 55-63.

[30] De Jong R. Adult age differences in goal activation and goal maintenance. Euro J Cognit Psychol 2001; 13: 71-89.

[31] Stern JA, Oster PJ, Newport K. Reaction time measures, hemispheric specialization, and age. In: Poon, LW, Ed. Aging in the 1980s Washington, DC: American Psychology Association 1980.

[32] Strayer DL, Kramer AF. Aging and skill acquisition: Learningperformance distinctions. Psychol Aging 1994; 9: 589-605.

[33] Grafton ST, Salidis J, Willingham DB. Motor learning of compatible and incompatible visuomotor maps. J Cogn Neurosci 2001; 13: 217-31

[34] Wada Y, Kawabata Y, Kotosake S, Yamamoto K, Kitazawa S, Kawato M. Acquisition and contextual switching of multiple internal models for difference viscous force-fields. Neurosci Res 2003; 46: 319-31.

(C) Zupanc et al.; Licensee Bentham Open.

This is an open access article licensed under the terms of the Creative Commons Attribution Non-Commercial License (http: //creativecommons.org/licenses/ by-nc/3.0/) which permits unrestricted, non-commercial use, distribution and reproduction in any medium, provided the work is properly cited. 